DOI

\title{
СОВРЕМЕННЫЕ АСПЕКТЫ ЛЕЧЕНИЯ ПАЦИЕНТОВ С ФИБРИЛЛЯЦИЕЙ ПРЕДСЕРДИЙ НОВЫМИ ПЕРОРАЛЬНЫМИ АНТИКОАГУЛЯНТАМИ
}

\section{MODERN ASPECTS OF TREATMENT OF PATIENTS WITH ATRIAL FIBRILLATION WITH NEW ORAL ANTICOAGULANTS}

\author{
В.И. Вишневский, Ю.Н. Панина \\ V.I. Vishnevskij, Ju.N. Panina \\ Орловский государственный университет имени И.С. Тургенева, \\ Россия, 302026, г. Орёл, ул. Комсомольская, д. 95 \\ Oryol State University named by I.S. Turgenev, \\ 95 Komsomolskaya St, Orel, 302026, Russia \\ E-mail: vishnevsky.orel@mail.ru, doc.panina@yandex.ru
}

\begin{abstract}
Аннотация
В обзорной статье рассматриваются современные аспекты применения новых пероральных антикоагулянтов у пациентов с фибрилляцией предсердий (ФП). Рассмотрены слабые и сильные стороны антикоагулянтов. Рассмотрены вопросы назначения антикоагулянтов пациентам с клапанной и неклапанной фибрилляцией предсердий. Особое внимание уделено стратификации риска тромбоэмболий при мерцательной аритмии. Приведено сравнение новых оральных антикоагулянтов (НОАК) и варфарина. Описаны современные новые пероральные антикоагулянты, зарегистрированные в Российской Федерации. Рассмотрены особенности применения препаратов у пациентов с патологией печени, острым коронарным синдромом, почечной недостаточностью. Рассмотрены принципы перевода больных с одного антикоагулянта на другой. Предоставленные подходы могут помочь практическим врачам в выборе наиболее приемлемой и рациональной схемы ведения пациента с ФП.
\end{abstract}

\begin{abstract}
The review article describes current aspects of the use of new oral anticoagulants in patients with AF. Weaknesses and strengths of anticoagulants are considered. The questions of anticoagulants administration to patients with valvular and non-valvular atrial fibrillation are considered. Particular attention is paid to stratifying the risk of thromboembolism in atrial fibrillation. A comparison of new oral anticoagulants and warfarin is given. Modern new oral anticoagulants registered in the Russian Federation are described. The features of the use of drugs in patients with liver pathology, acute coronary syndrome, and renal failure are considered. Aspects of administration of new oral anticoagulants in patients with atrial fibrillation during cardioversion are considered. The principles of transferring patients from one anticoagulant to another are considered. The provided approaches can help practitioners in choosing the most acceptable and rational management scheme for a patient with AF.
\end{abstract}

Ключевые слова: фибрилляция предсердий, тромбоэмболии, ишемический инсульт, новые оральные антикоагулянты, ривароксабан, дабигатран, апиксабан.

Keywords: atrial fibrillation, thromboembolism, ischemic stroke, new oral anticoagulants, rivaroxaban, dabigatran, apixaban.

\section{Актуальность}

Фибрилляция предсердий (ФП) является самым частым нарушением ритма сердца [Бокерия, 2005]. Распространенность в популяции составляет 1-2\%, а в популяции лиц старше 80 лет - $15 \%$. У пациентов с ФП риск развития ишемического инсульта в 3-6 раз выше по сравнению с таковыми в общей популяции [Кобалова, Шавров, 2018]. Кроме то- 
го, риск возникновения инсульта не зависит от формы ФП. При пароксизмальной, персистирующей и хронической ФП риск одинаков. Современные клинические рекомендации по ведению пациентов с ФП рекомендуют длительное антикоагулянтное лечение для профилактики инсульта [Остроумова и др., 2015]. Тромбоэмболические заболевания являются основной причиной заболеваемости и смертности в развитых странах мира.

ФП - это патологический нерегулярный ритм сердца с хаотической генерацией возбуждения в предсердиях. При ФП происходит стаз крови в левом предсердии, а точнее, в ушке левого предсердия. Стаз крови приводит к формированию тромба, части которого отрываются и с кровотоком попадают в головной мозг. Это так называемый кардиоэмболический инсульт [Дамулин, Андреев, 2015].

Следует различать клапанную и неклапанную ФП. Клапанная ФП - это ФП на фоне умеренного или тяжелого митрального стеноза, требующего хирургической коррекции или наличия механического протеза клапана. В лечении такой формы ФП используют длительный прием антитромботических средств [Клеткина, Ефремова, 2014]. Применение новых оральных антикоагулянтов (НОАК) у пациентов с протезированным клапаном сердца является небезопасным. В исследовании RE-ALIGN пациенты с протезированными сердечными клапанами принимали дабигатран. Это было сопряжено с более высокой частотой тромбоэмболических осложнений и больших кровотечений, чем при терапии варфарином, ввиду чего исследование было досрочно прекращено. Таким образом, пациентам с клапанной ФП в настоящее время показано назначение только варфарина [Ефремова и др., 2013; Новикова, Воловченко, 2016].

Напротив, при неклапанной форме ФП наряду с применением варфарина не только одобрено, но и рекомендовано использование НОАК. У пациентов с данной формой ФП применение варфарина оправдано только при высокой степени приверженности к лечению и хорошем контроле МНО.

Варфарин и НОАК. Многие лекарственные препараты были открыты случайно, например, варфарин. Сначала он использовался в качестве яда для грызунов, позже его разрешили к применению у людей в качестве антикоагулянта. И только спустя более 20 лет его применения у пациентов был установлен механизм действия варфарина. Варфарин - это антикоагулянт непрямого действия. Механизм действия препарата состоит в нарушении метаболизма витамина К в результате угнетения фермента эпоксидредуктазы. В России препарат был зарегистрирован только в 2001 г. Следует также отметить, что в качестве единственной доступной долгосрочной пероральной антикоагулянтной терапии в течение более 50 лет применялся именно варфарин [Фонякин, 2016].

Следует сказать, что доказательная база варфарина в отношении первичной и вторичной профилактики ишемического инсульта у пациентов с ФП огромна. По результатам мета-анализа, проведенного Hart R.G. и соавт., варфарин уменьшает вероятность инсульта у пациентов с неклапанной ФП в среднем на $60 \%$ по сравнению с группой плацебо-контроля, на $40 \%$ - в сравнении с аспирином, а также на $26 \%$ снижает общую смертность [Марцевич, Лукина, 2017].

Но время случайных открытий лекарственных препаратов прошло. Сегодня ученые моделируют будущий препарат. Заранее задают ему необходимые свойства.

НОАК. Препараты нового поколения разрабатываются с целью сделать профилактику и лечение тромбозов и тромбоэмболий более эффективной и безопасной. На сегодняшний день в Российской Федерации зарегистрированы следующие НОАК: дабигатран, ривароксабан, апиксабан [Бокерия, Копалиани, 2016].

Так, компания Bayer HealthCare начала разработку прямого ингибитора Ха фактора в 1998 году. Из 200000 соединений отобрали несколько с нужными свойствами. Длительные исследования, проведенные на лабораторных животных, выделили вещество ривароксабан. И только 16 сентября 2008 г. ривароксабан был внедрен в клиническую практику в Канаде, а 30 сентября 2008 г. - еще в 100 странах мира. Препарат был одобрен для профилактики венозных тромбозов и тромбоэмболии после протезирования коленных и тазо- 
бедренных суставов. С 2010 г. препарат стал использоваться у пациентов с фибрилляцией предсердий для профилактики инфаркта мозга [Perzborn et al., 2011].

18 марта 2008 г. дабигатран (от компании Boehringer Internationl GmbH) разрешен к использованию для профилактики тромбоэмболических заболеваний при протезировании и у пациентов с ФП с 2010 г.

Апиксабан разработан компанией Pfizer/Bristol-Myers. В 2012 г. препарат был одобрен в Европе. А спустя 2 года - в США для лечения и профилактики тромбоза глубоких вен и тромбоэмболий.

Дабигатран - это первый НОАК, эффективность и безопасность которого в предупреждении тромбоэмболических осложнений при ФП была доказана в многочисленных клинических испытаниях. Это первый препарат из группы НОАК, который получил одобрение для клинического применения у пациентов с неклапанной ФП. Дабигатран является селективным конкурентным прямым ингибитором тромбина обратимого действия, применяется в виде пролекарства, который после всасывания быстро превращается под действием эстераз плазмы в активный дабигатран. Активная молекула вещества связывается с активным сайтом молекулы тромбина гидрофобными связями, благодаря чему становится невозможным превращение фибриногена в фибрин, то есть блокируется заключительный этап каскада коагуляции и образования тромба [Фонякин, 2014]. Биодоступность дабигатрана 60 \%, объем распределения 50-70 л., период полураспада 12-17 ч., метаболизируется дабигатран почками на $80 \%$, связывается с белками - $35 \%$ [Boehringer Ingelheim, 2013.]

Ривароксабан является высокоселективным прямым ингибитором Ха фактора свертывания. Данный фактор является основным в каскаде свертывания, образует комплекс с Va фактором, кальцием и тромбоцитарным фосфолипидом и называется протромбиназой. Последняя преобразует протромбин в тромбин. Таким образом, ривароксабан не ингибирует непосредственно тромбин, а уменьшает его образование путем блокирования активности фактора Ха. Механизм действия препарата обеспечивает более эффективное предотвращение фибринообразования, чем инактивация тромбина, поскольку одна молекула фактора Ха вызывает образование около 1000 молекул тромбина [Сторожаков и др., 2013]. Биодоступность ривароксабана 60-80\%, объем распределения 50 л., период полураспада 5-13 ч., метаболизируется препарат почками на 33 \% и печенью на 66 \%, связывается с белками - более $90 \%$ [Titusville, 2013].

Апиксабан является прямым специфическим селективным ингибитором Ха фактора, катализирующего преобразование протромбина в тромбин. Соответственно, как и ривароксабан, он не оказывает прямого действия на тромбин, а регулирует образование тромбина посредством ингибирования Ха. Биодоступность апиксабана 50 \%, объем распределения 21 л., период полураспада 9-14 ч., метаболизируется препарат почками на $25 \%$ и печенью на $75 \%$, связывается с белками - $87 \%$ [Princeton, 2012].

Сравнение варфарина и НОАК. Начало действия НОАК более быстрое, чем у варфарина, а фармакокинетический эффект предсказуем. Не требуется постоянный лабораторный контроль МНО. Варфарин оказывает свой антикоагулянтный эффект благодаря ингибированию синтеза витамин К-зависимых факторов свертывания (II, VII, IX, X). Начало терапии варфарином требует индивидуальный подбор дозы препарата. Недостаточная доза препарата может привести к тромбозу, а чрезмерная - к кровотечению. Кроме того, варфарин ингибирует белки $\mathrm{C}$ и $\mathrm{S}$, что повышает риск развития тромбоза в начале терапии. Медленное начало действия, узкое терапевтическое окно, многочисленные лекарственные и пищевые взаимодействия, необходимость постоянного контроля МНО являются основными ограничениями применения варфарина у пациентов с ФП. НОАК оказывают свое терапевтическое действие путем непосредственного подавления одного из факторов свертывания. Так, дабигатран нацелен на ІІа фактор, ривароксабан и апиксабан на Ха. Ограничения по использованию НОАК включают в себя высокую стоимость, про- 
тивопоказания для пациентов с тяжелой почечной недостаточностью, а также отсутствие антидота [Бокарев, Кондратьева, 2016].

Большинство НОАК доказали свои преимущества по сравнению с варфарином в профилактике ФП. НОАК не уступают или эффективнее варфарина в профилактике инсульта и тромбоэмболии, меньше риск внутричерепных кровоизлияний по сравнению с варфарином.

Стратификация риска тромбоэмболических осложнений ФП. Результаты многочисленных исследований позволили определить ряд факторов, ассоциированных с повышенным риском ишемического инсульта у больных с ФП, что повлекло за собой разработку шкалы по оценке вероятности его развития [Нурашева и др., 2017]. Для этого была создана шкала CHA2DS2-VASc. Для оценки используется сумма баллов для конкретного пациента. Риск развития мозговой сосудистой катастрофы и других тромбоэмболических осложнений возрастает пропорционально увеличению суммы баллов по шкале. Факторы риска по своей значимости разделены на две категории: «большие» и «клинически значимые небольшие». К «большим» отнесли наличие в анамнезе инсульта, ТИА или системной тромбоэмболии, возраст 75 лет и более. Каждый такой фактор оценивается в 2 балла. Ко второй группе факторов относятся ХCH, артериальная гипертензия, сахарный диабет, женский пол, возраст 65-74 года, наличие сосудистых заболеваний (перенесенный инфаркт миокарда, атеросклеротические бляшки в аорте, сосудистые заболевания периферических артерий). Каждый такой фактор оценивается в 1 балл. Так, если сумма равна 1, то риск развития инсульта составляет 1,3\% в год, если 2 балла - 2,2 \% в год, при максимально возможных 9 баллах - 15,2\%. Подсчитав полученные баллы по наличию факторов риска, можно легко определиться с рекомендованной в данном случае терапией. Согласно рекомендациям, если у пациента есть ФП и хотя бы один из перечисленных факторов риска, то ему уже показана антикоагулянтная терапия [Галявич, 2012].

Однако не все так идеально при использовании антикоагулянтов. Любая антитромботическая терапия сопряжена с риском развития геморрагических событий. Экспертами для оценки риска осложнений при использовании оральных антикоагулянтов была создана шкала - HAS-BLED. Итак, факторами кровотечений, согласно шкале, являются артериальная гипертензия, дисфункция почек и печени, инсульт и кровотечение в анамнезе, нестабильный уровень МНО при лечении варфарином, возраст старше 65 лет, употребление некоторых лекарственных препаратов или алкоголя. Максимальное число баллов, которое может набрать пациент, равно 9, но уже при наличии трех баллов и более риск кровотечений считается высоким. Однако оговаривается, что высокий риск развития кровотечений не может оказывать влияние на принятие решения о назначении антитромботической терапии. Три балла и более по шкале HAS-BLED - это призыв к более осторожному назначению антикоагулянтов, более тщательному контролю, а в ряде случаев - к коррекции дозы [Шубик, 2014].

Общие аспекты применения НОАК у пациентов с ФП. В новой редакции практического руководства European Heart Rhythm Association имеется указание на необходимость ежегодного контроля за пациентами, принимающими НОАК. Обязательным является оценка уровня гемоглобина, показателей функции печени и почек. У пациентов со сниженной функцией почек, а также пациентов в пожилом и старческом возрасте контроль вышеназванных параметров следует проводить несколько раз в год. Функцию почек оценивают путем расчета СКФ по формуле Cockroft-Gault. Ни один НОАК не может быть назначен при СКФ менее 15 мл/мин. Сниженные дозы ривароксабана до 15 мг в сутки или апиксабана до 2,5 мг 2 раза в сутки могут применяться при СКФ равной 15-30 мл/мин. Дабигатран не может использоваться при СКФ менее 30 мл/мин, но при СКФ равной 30-50 мл/мин допустимо назначение данного НОАК в дозах 110 ил 150 мг 2 раза в сутки [Фонякин, 2014].

Перед оперативным лечением следует отменить НОАК, отменяют за 24-48 часов. 
Ишемический инсульт, возникший на фоне приема НОАК. Возобновление приема антикоагулянта следует рассматривать через 3-14 дней после мозговой катастрофы в зависимости от степени неврологического дефицита и при исключении геморрагической трансформации по данным КТ.

ФП и ОКС. Частота возникновения ФП у пациентов с ОКС колеблется в широких пределах от $10 \%$ до $21 \%$ и увеличивается с возрастом пациентов. В популяции ФП связана с повышенным уровнем госпитальной смертности $(25,3$ \% при ФП против $16.0 \%$ без ФП), 30-дневной смертности (29,3\% против 19,1\%), смертности в течение первого года после перенесенного ОКС (48,3 \% против 32,7\%). Таким образом, ФП является независимым фактором смерти во время госпитализации пациентов по поводу ОКС. Частота инсульта выше у пациентов с ИМ и ФП, чем у пациентов без ФП (3,1 \% для пациентов с ФП против 1,3 \% с синусным ритмом). Таким образом, ФП является независимым предиктором плохого отдаленного исхода у пациентов с ОКС. Пациенты с ОКС нуждаются в двойной антиагрегантной терапии. При ФП для профилактики инсульта может потребоваться добавление варфарина либо НОАК (тройная терапия). Но продолжительность такой терапии должна быть минимизирована от 4 до 6 недель. Возможен также вариант двойной терапии - пероральный антикоагулянт + клопидогрел. После периода такой двойной терапии в течение 12 месяцев, в случае проведения ЧКВ, пациента переводят на монотерапию НОАК [Канорский, Гиляревский, 2018].

Кардиоверсия (фармакологическая и электрическая). Общеизвестно, что для пациентов с ФП или ТП продолжительностью более 48 часов или при аритмии неизвестной давности рекомендуется антикоагулянтная терапия варфарином или НОАК не менее 3-х недель до и не менее 4 недель после кардиоверсии, независимо от оценки CHA2DS2VASc. НОАК более эффективны и безопасны, чем варфарин. В ретроспективных исследованиях оценивался риск развития ТЭ у пациентов после кардиоверсии без последующей антикоагуляции. Риск развития ТЭ был в 5 раз выше [Craig, Wann, 2019].

ФП и тяжелое поражение печени. Применение НОАК противопоказано у пациентов с заболеваниями печени, сопровождающимися коагулопатией и кровотечениями, с циррозом печени класса $\mathrm{C}$ по Чайлду - Пью. Дабигатран и апиксабан могут применяться у больных с циррозом печени класса В по Чайлду - Пью, но с осторожностью.

Применение НОАК после мозгового кровоизлияния. После внутричерепного кровотечения возобновление приема НОАК начинают через 4-8 недель.

Применение НОАК после ЖКК. После ЖКК возобновление приема НОАК начинают через 4-7 недель [Канорский и др., 2018].

Перевод больных на другой режим антикоагулянтной терапии. Перевод больных с приема варфарина на прием НОАК. Если МНО менее 2.0, то НОАК может быть назначен немедленно. Если МНО составляет 2,0-2,5, то предпочтительнее назначать НОАК на следующий день. При МНО более 2,5 учитывают МНО и время полувыведения варфарина (36-48 часов). Прием НОАК может быть назначен при МНО 3,0 и менее для ривароксабана, 2,0 и менее для апиксабана и дабигатрана.

Перевод больных с НОАК на варфарин. Учитывая медленное начало действия варфарина, может потребоваться 5-10 дней до достижения терапевтического диапазона МНО. Следовательно, НОАК и варфарин должны назначаться одновременно до тех пор, пока МНО не достигнет необходимого терапевтического диапазона.

Перевод с приема НОАК на парентеральное введение антикоагулянтов. Парентеральное введение гепаринов может быть начато в момент предполагавшегося применения очередной дозы НОАК.

Перевод с гепаринов на НОАК. Применение НОАК может начинаться через 2 часа после прекращения внутривенного введения нефракционированного гепарина. Применение НОАК может начинаться в момент предполагаемого применения следующей дозы низкомолекулярных гепаринов [Канорский и др., 2018]. 


\section{Заключение}

Таким образом, профилактика ишемического инсульта при ФП за последнее десятилетие вышла на новый качественный уровень. Сегодня НОАК занимают лидирующие позиции в качестве препаратов выбора при ФП. Фиксированная доза, отсутствие лекарственных и пищевых взаимодействий, отсутствие потребности в постоянном мониторинге МНО позволили данной группе препаратов занять ведущие позиции среди антитромботических средств, используемых в профилактике сосудистых мозговых катастроф. Можно прогнозировать, что в будущем будут проведены новые клинические исследования, которые откроют новые возможности НОАК, расширят показания к применению данных препаратов.

\section{Список литературы}

1. Бокарев И.Н., Кондратьева Т.Б. 2016. Новые оральные антикоагулянты в клиничской практике. Эффективность и проблемы. Клиническая медицина. 94 (5): 383-387.

2. Бокерия Л.А. 2005. Профилактика инсульта при фибрилляции предсердий. Анналы аритмологии. 3: 45-55.

3. Бокерия О.Л., Копалиани Т.И. 2016. Откажемся ли мы от варфарина? Анналы аритмологии. 13 (2): 87-95.

4. Галявич А.С. 2012. Современные подходы к профилактике инсультов при фибрилляции предсердий. Новые технологии в медицине. Кардиология. 5: 93-97.

5. Дамулин И.В., Андреев Д.А. 2015. Фибрилляция предсердий. Российский медицинский журнал. 6: 41-45.

6. Ефремова О.А., Клеткина А.С., Камышникова Л.А., Беляева С.С. 2013. Применение антикоагулянтов у больных с фибрилляцией предсердий и пороками сердца. Научные ведомости Белгородского государственного университета. Серия: Медицина. Фармация. 25 (168): 118-121.

7. Канорский С.Г., Гиляревский С.Р. Тарасов А.В., Жук В.С., Явелов И.С. 2018. Новые рекомендации EHRA по антикоагулянтной терапии у больных с фибрилляцией предсердий: комментарии российских экспертов. Международный журнал сердца и сосудистых заболеваний. 6 (19): $45-56$.

8. Клеткина А.С., Ефремова О.А. 2014. Антитромботическая терапия фибрилляции предсердий. Научный результат. Серия: Медицина и фармация. 1 (1): 24-30.

9. Кобалова Ж.Д., Шавров А.А. 2018. Практические аспекты антикоагулянтной терапии дабигатраном у пациентов с фибрилляцией предсердий и АГ. Кардиология. 58: 42-55.

10. Марцевич С.Ю., Лукина Ю.В. 2017. Варфарин и его значение в эру новых оральных антикоагулянтов. Вопросы контроля эффективности и безопасности лечения. Рациональная Фармакотерапия в Кардиологии. 13: 699-705.

11. Новикова Н.А., Воловченко А.Н. 2016. Варфарин: место в современной антикоагулянтной терапии. Специализированный медицинский журнал. 1: 50-58.

12. Нурашева Э.Е., Мырзагулова А.О., Текебаева Л.А., Утеулиев Е.С. 2017. Возможности современной антикоагулянтной терапии у пациентов с фибрилляцией предсердий и ишемическим инсультом. Вестник КазНМУ. 4: 116-118.

13. Остроумова О.Д., Воеводина Н.Ю., Павлеева Т.Ф., Пиксина Г.Ф., Голобородова И.В. 2015. Профилактика инсульта у пациента с фибрилляцией предсердий и сопутствующими заболеваниями. Системные гипертензии. 15 (2): 55-59.

14. Сторожаков Г.И., Борисов С.Н., Гендлин Г.Е., Мелехов А.В. 2013. Применение пероральных антикоагулянтов при фибрилляции предсердий: современное состояние проблемы и новые возможности. Архив внутренней медицины. 2: 57-64.

15. Фонякин А.В. 2014. Дабигатрана этексилат при неклапанной фибрилляции предсердий в реальной практике и перспективы его применения для профилактики инсульта. Неврология, нейропсихиатрия, психосоматика. 6 (2): $44-50$.

16. Фонякин А.В. 2014. Современные рекомендации и перспективы применения новых пероральных антикоагулянтов при неклапанной фибрилляции предсердий. Неврология, нейропсихиатрия, психосоматика. 4: 19-25.

17. Шубик Ю.В. 2014. Антитромботическая терапия при фибрилляции предсердий: новые пероральные антикоагулянты. Медицинский совет. 11: 38-48. 
18. Craig T., Wann L.S. 2019. Guideline for the Management of Patients With Atrial Fibrillation. P. 52.

19. Eliquis (apixaban), package insert. Princeton, N.J.: Bristol-Myers Squibb; Dec, 2012.

20. Perzborn E., Roehrig S., Straub A., Kubitza D., Misselwitz F 2011. The discovery and development of rivaroxaban, an oral, direct factor Xa inhibitor. Nature reviews. 10: 61-75.

21. Pradaxa (dabigatran), package insert. Ridgefield, Conn.: Boehringer Ingelheim; Apr, 2013.

22. Xarelto (rivaroxaban), package insert. Titusville, N.J.: Janssen; Mar, 2013.

\section{References}

1. Bokarev I.N., Kondrat'eva T.B. 2016. Novye oral'nye antikoaguljanty v klinichskoj praktike. Jeffektivnost' i problemy [New oral anticoagulants in medicine practice. Efficiency and problems]. Klinicheskaja medicina. 94 (5): 383-387.

2. Bokerija L.A. 2005. Profilaktika insul'ta pri fibrilljacii predserdij [Prevention of stroke on patients with atrial fibrillation]. Annaly aritmologii. 3: 45-55.

3. Bokerija O.L., Kopaliani T.I. 2016. Otkazhemsja li my ot varfarina? [Can we refuse of warfarin?] Annaly aritmologii. 13 (2): 87-95.

4. Galjavich A.S. 2012. Sovremennye podhody k profilaktike insul'tov pri fibrilljacii predserdij. Novye tehnologii $\mathrm{v}$ medicine [Modern approaches of prevention of strokes with atrial fibrillation. New technologies in medicine]. Kardiologija. 5: 93-97.

5. Damulin I.V., Andreev D.A. 2015. Fibrilljacija predserdij [Atrial fibrillation]. Rossijskij medicinskij zhurnal. 6: 41-45.

6. Efremova O.A., Kletkina A.S., Kamyshnikova L.A., Beljaeva S.S. 2013. Primenenie antikoaguljantov u bol'nyh s fibrilljaciej predserdij i porokami serdca [Analysis of therapy with anticoagulants in patients who have malformations of the heart and atrial fibrillation]. Nauchnye vedomosti Belgorodskogo gosudarstvennogo universiteta. Serija: Medicina. Farmacija. 25 (168): 118-121.

7. Kanorskij S.G., Giljarevskij S.R. Tarasov A.V., Zhuk V.S., Javelov I.S. 2018. Novye rekomendacii EHRA po antikoaguljantnoj terapii u bol'nyh s fibrilljaciej predserdij: kommentarii rossijskih jekspertov [New EHRA recommendations on anticoagulant therapy in patients with atrial fibrillation: comments of Russian experts]. Mezhdunarodnyj zhurnal serdca i sosudistyh zabolevanij. 6 (19): 45-56.

8. Kletkina A.S., Efremova O.A. 2014. Antitromboticheskaja terapija fibrilljacii predserdij [Antithrombotic atrial fibrillation therapy]. Nauchnyj rezul'tat. Serija: Medicina i farmacija. 1 (1): 24-30.

9. Kobalova Zh.D., Shavrov A.A. 2018. Prakticheskie aspekty antikoaguljantnoj terapii dabigatranom u pacientov s fibrilljaciej predserdij i AG [Practical aspects of anticoagulant therapy with dabigatran in patients with atrial fibrillation and hypertension]. Kardiologija. 58: 42-55.

10. Marcevich S.Ju., Lukina Ju.V. 2017. Varfarin i ego znachenie v jeru novyh oral'nyh antikoaguljantov. Voprosy kontrolja jeffektivnosti i bezopasnosti lechenija [Варфарин и его значение в эру новых оральных антикоагулянтов. Вопросы контроля эффективности и безопасности лечения]. Racional'naja Farmakoterapija v Kardiologii. 13: 699-705.

11. Novikova N.A., Volovchenko A.N. 2016. Varfarin: mesto v sovremennoj antikoaguljantnoj terapii [Warfarin: a place in modern anticoagulant therapy]. Specializirovannyj medicinskij zhurnal. 1: 50-58.

12. Nurasheva Je.E., Myrzagulova A.O., Tekebaeva L.A., Uteuliev E.S. 2017. Vozmozhnosti sovremennoj antikoaguljantnoj terapii u pacientov s fibrilljaciej predserdij i ishemicheskim insul'tom [Possibilities of modern anticoagulant therapy in patients with atrial fibrillation and ischemic stroke]. Vestnik KazNMU. 4: 116-118.

13. Ostroumova O.D., Voevodina N.Ju., Pavleeva T.F., Piksina G.F., Goloborodova I.V. 2015. Profilaktika insul'ta u pacienta s fibrilljaciej predserdij i soputstvujushhimi zabolevanijami [Prevention of stroke in patients with atrial fibrillation and comorbidities]. Sistemnye gipertenzii. 15 (2): 55-59.

14. Storozhakov G.I., Borisov S.N., Gendlin G.E., Melehov A.V. 2013. Primenenie peroral'nyh antikoaguljantov pri fibrilljacii predserdij: sovremennoe sostojanie problemy i novye vozmozhnosti [The use of oral anticoagulants in atrial fibrillation: current state of the problem and new opportunities]. Arhiv vnutrennej mediciny. 2: 57-64.

15. Fonjakin A.V. 2014. Dabigatrana jeteksilat pri neklapannoj fibrilljacii predserdij v real'noj praktike i perspektivy ego primenenija dlja profilaktiki insul'ta [Dabigatran etexilate in non-valvular atrial fibrillation in real practice and prospects of its use for stroke prevention]. Nevrologija, nejropsihiatrija, psihosomatika. 6 (2): 44-50. 
16. Fonjakin A.V. 2014. Sovremennye rekomendacii i perspektivy primenenija novyh peroral'nyh antikoaguljantov pri neklapannoj fibrilljacii predserdij [Current recommendations and prospects for the use of new oral anticoagulants in non-valvular atrial fibrillation]. Nevrologija, nejropsihiatrija, psihosomatika. 4: 19-25.

17. Shubik Ju.V. 2014. Antitromboticheskaja terapija pri fibrilljacii predserdij: novye peroral'nye antikoaguljanty [Antithrombotic therapy for atrial fibrillation: new oral anticoagulants]. Medicinskij sovet. 11: 38-48.

18. Craig T., Wann L.S. 2019. Guideline for the Management of Patients With Atrial Fibrillation. p. 52.

19. Eliquis (apixaban), package insert. Princeton, N.J.: Bristol-Myers Squibb; Dec, 2012.

20. Perzborn E., Roehrig S., Straub A., Kubitza D., Misselwitz F 2011. The discovery and development of rivaroxaban, an oral, direct factor Xa inhibitor. Nature reviews. 10: 61-75.

21. Pradaxa (dabigatran), package insert. Ridgefield, Conn.: Boehringer Ingelheim; Apr, 2013.

22. Xarelto (rivaroxaban), package insert. Titusville, N.J.: Janssen; Mar, 2013.

\section{Ссылка для цитирования статьи Reference to article}

Вишневский В.И., Панина Ю.Н. 2019. Современные аспекты лечения пациентов с фибрилляцией предсердий новыми пероральными антикоагулянтами. Актуальные проблемы медицины, 43(1): 65-72. DOI

Vishnevskij V.I., Panina Ju.N. 2019. Modern aspects of treatment of patients with atrial fibrillation with new oral anticoagulants. Challenges in Modern Medicine, 43(1): 65-72 (in Russian). DOI 